\title{
Establishment and Practice of Training Program for Undergraduate Talents of Agricultural Industry
}

\author{
Lijia $\mathrm{Xu}^{1, \mathrm{a}}$ and Zhiliang Kang ${ }^{1, \mathrm{~b}^{*}}$ \\ ${ }^{1}$ College of Mechanical and Electronic Engineering, Sichuan Agricultural University, Ya'an, 625014, \\ China \\ aLijiaxu13@163.com, 'hiliangkang96@163.com \\ *The corresponding author
}

Keywords: Agricultural engineering; Talent training program; Study service network; Core skill of course

\begin{abstract}
Aiming at training inter-disciplinary agricultural engineering talents with sound theoretical basis and strong practical capacity and focusing on fostering students' consciousness of innovation, engineering capacity and pioneering capacity, we integrated reform of talent training program with requirements of economy, society and regional development, optimized theoretical teaching system, offered skill training and pioneering courses and realized fusion of multi-disciplinary and professional knowledge so as to establish training program for undergraduate talents of new agricultural engineering. Through many years exploration and practice, this talent training program achieved favorable results of training of undergraduate talents of agricultural engineering.
\end{abstract}

\section{Introduction}

Agricultural modernization is a development goal of China in the 21 st century. With an important position, the discipline of agricultural engineering utilizes advanced engineering technology to develop agricultural resources, create agricultural production environment and realized modernization of production conditions, so it is one of substantive characteristics of agricultural modernization [1-3]. China is short of innovative talents with agricultural engineering technology, especially in Western China regions. Investigation found that traditional undergraduate talents of agricultural engineering lack of holistic thinking and systematical design, so they cannot satisfy agricultural modernization's requirement to talents. Therefore, this paper focuses on training the practical ability and innovation ability of students, aims at establishing a scientific training program for undergraduate talents of agricultural engineering, integrates reform of talent training program with the needs of economy, society, industry and regional development in order to cultivate high-quality talents of agricultural engineering with sound theoretical basis and strong practical ability. This has profound significance in promoting the sustainable development of the agricultural economy and boosting development of China's agricultural modernization process, especially that of the western region.

\section{Problems in Training Program}

At present, there are many problems in course offering of agricultural engineering specialties: (1) knowledge range is narrow, talent training is over professionalized, horizontal expansion of fundamentality is insufficient, disciplines are less intercrossed, and training of professional talents is disconnected with requirement of local economy, industry; (2) course system is not perfect, and knowledge structure is irrational. Existing courses lay excessive stress on education of specialized courses, but overlook courses of basics, humanities, psychology, and entrepreneurship, pay attention to rational imparting and training, but give little care to edification of humanistic spirit such that it cannot form a comprehensive and rational knowledge structure covering engineering, science, economy humanities; (3) the courses lack of the link of comprehensive ability training and practice, and practical teaching normally focus on verification and demonstration of theory learned, while 
providing little practice activities for students to participate in design manufacture and scientific research resulting in students' ability of analyzing and solving practical engineering problems is greatly under social demand for engineering talent[4-5].

\section{Content of Establishment of Talent Training Program}

Research the Teaching Methods and Programs for Training S\&T Innovative Talents. It shall break barriers of each agricultural engineering specialty and achieve integration of multidisciplinary knowledge system, on this account we'll be able to establish scientific curriculum system, offer entrepreneurship training courses together with enterprises and other institutions, get students' innovative spirit and quality of entrepreneurship inspired, cultivated and exercised through theoretical reference, case analysis, simulated experiments and contests, establish the entrepreneurship course system and implement the course mode of training entrepreneurship talents, and give consideration to both academic education and occupational qualification [6].

Achieve Extraction of Core Skills of Courses. Business backbones of each agricultural engineering specialty and experts of enterprises and public institutions jointly study the core skills of each specialty, training methods and evaluation indices, screen backbone major course, extract core skills of backbone courses, and make it be singularized, modularized and hierarchicalized and integrate talent training with regional economy and industrial development.

Improve the Practical Teaching System. Divide experimental module so as to make each experiment module is independent on teaching but interrelated on content, each experiment module includes training on professional skills, and focus on cultivation of the students' practical ability and awareness of innovation [7]. Meanwhile, it shall implement all kinds of student centered and teacher oriented interactive experimental teaching and theoretical teaching modes such as heuristic, problem-based, participatory and problem-based ones, carry out skill contests and teacher scientific research programs relying on each specialty, organizes students of similar specialties to form innovative team and set up S\&T interest programs so as to cultivate the students' engineering abilities.

\section{Framework of Talents Training Program}

The framework of talents training program covers three major aspects, i.e. setting of basic courses, specialized course and study service network for each broad specialty category of agricultural engineering, the specific content of which includes amendment and setting of teaching programs, syllabus and course system, traning of required disciplinary theoretical system and study methods for students. When agricultural engineering course system is establishing, it shall strive to achieve mutual penetration, intercrossing and fusion between multiple disciplines and technical fields. The framework of talents training program is as shown in Fig. 1.

Training program is formulated following the principles of "industry-oriented, ability-based and refined goals", which mainly includes basic courses and specialized courses, invite experts of relevant enterprises and institutions to participate in development of the training program. When course system is establishing, it shall realize fusion of disciplines and specialties and also pay attention to academic education and cultivation of occupational qualification abilities[7]; when teaching methods and measures are reforming, it shall consider "integration" of classroom teaching and online teaching, "integration" of theoretical teaching and practical teaching; and giving consideration to academic standard and requirements of industries and enterprises in integrated assessment evaluation indices.

The Diversification of the Curriculum Setting. Strengthen humanity courses, realize delivery of traditional culture, increase psychological courses, foster students' flexible ability and add career courses and interdisciplinary courses for character development [8]. With the principle of "industry and enterprise satisfaction", adjust and optimize the curriculum setting, open some career courses concentrated on research and perfect connection with enterprises and organizations, and enable students to make choice according to their specialties. Career course design includes: (1) theory reference, which is to absorb and success current career theory critically and with choice to avoid 
detours in the future career activities; (2) case analysis, which is to analyze the growth of successful people in career through selection of successful career cases and set examples in career for students; (3) simulative experiment, which is to simulate a career program with modern scientific technology based on study of theory courses and analyze various career factors and make conclusion finally; (4) contest stimulation, which is to exercise students' innovative spirit and career quality through contests.

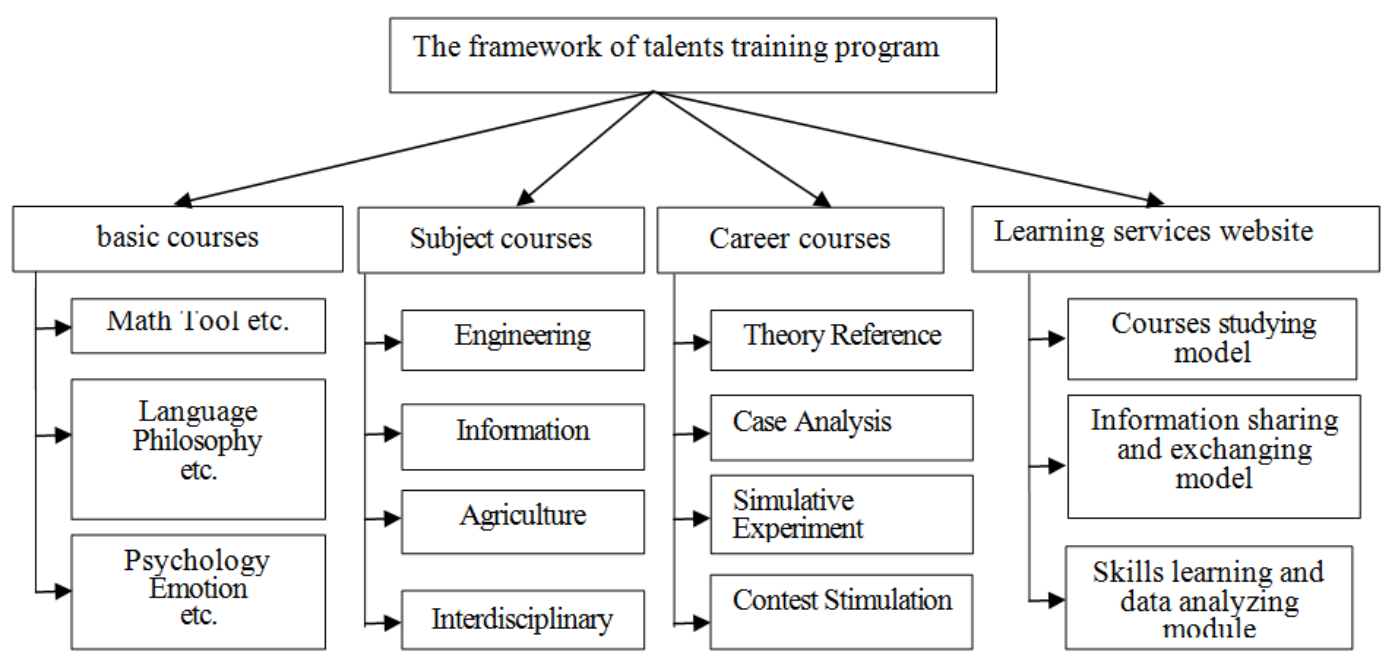

Figure 1. The framework of talents training program

Giving Prominence to Status of Backbone Courses. In revision of teaching program, some courses with outdated content are cancelled and class hours of some courses are shortened in the principle of advancing with the times, a special person is assigned for each specialty who takes charge of revision of teaching program, 3-5 backbone courses that represent core skills of this specialty most are screened to carry out key construction. Each backbone courses shall meet the following requirements: (1) Each course shall have a course team consisting of 3-5 teachers, of which one teacher with senior title serves as course responsible person in charge of planning and establishment of such course; (2) draw up the list and content of core skills of courses, and then students can enter professional lab to take skill training or study according to their own conditions; (3) construct course website and upload all relevant data of courses to such website for students to upload and download data or mutual exchange; (4) special fund supports course PPT construction and reform of teaching method, PPT shall be added with more animation simulated effect and more cases to make the boring theory be visualized and concretized [8]. With regard to teaching methods, it shall utilize interactive measures such as case-based, discussion-based and heuristic ones, add ordinary time practice modes of course training, course exercise, classroom test and course report, etc.

Singularization, Modularization and Hierarchicalization of Core Skills of Courses. After each specialty course of agricultural engineering is horizontally and vertically decomposed, it shall determine core skill points of the courses, and then carry out separate training by item and layer [9-10]. These skill points are not only core skills analyzed according to practical application and employment direction, but also manifestation of important knowledge points of backbone courses such that study of basic specialized courses can be intensified by carrying out training item by item. Select business backbone of each specialty and experts of relevant enterprises and institutions to jointly formulate skill points, skill trees as well as outline, items and evaluation standard of skill training plan as a basis for revising existing experimental and practical outline; optimize practical teaching content, and make it fully manifest changes of connotation of agricultural engineering disciplines on setting of teaching program, syllabus, course system and thesis topic selection and opening[11]. 
Taking study of the module of "combined design, assembly and mapping of bearing and gear drive" in mechanical design course for instance, the skill points required for finishing this module and corresponding skill tree are shown as Fig. 2.

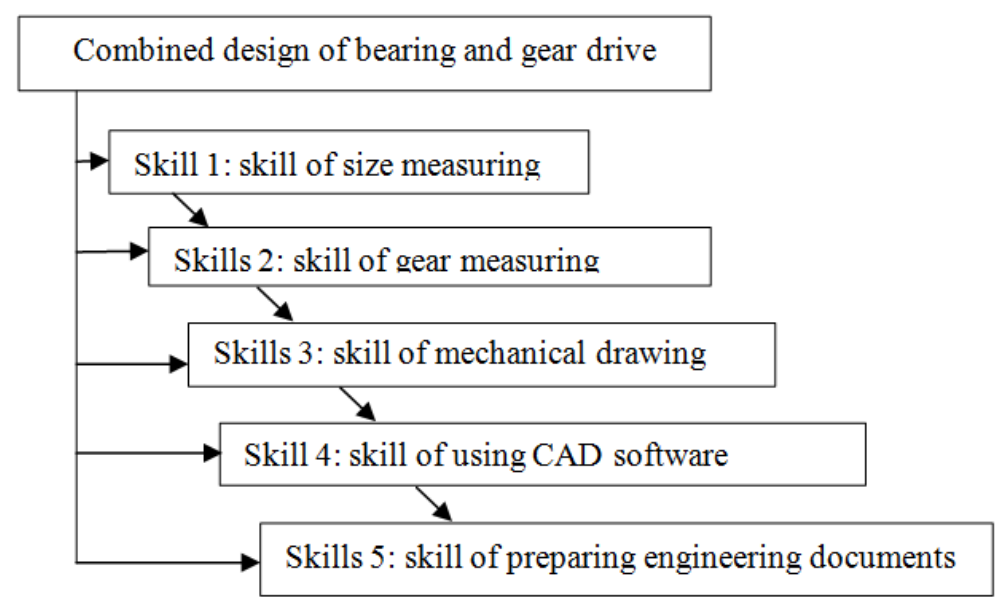

Figure 2. Skill tree of study module

Study Service Website. This study service website includes information sharing and communication module, course study module, skill learning progress and data analysis module.

(1) Information sharing and communication module. This module mainly releases the latest trend and all resources of disciplines, provides a platform for releasing news and employment information among teachers, students and cooperative units, provides video open class of different disciplines and study resources for choice resources shared courses in order to let students select courses of relevant discipline according to their own interest and abilities and realize fusion of multiple disciplines and specialties.

(2) Course study module. In the course study module, all of backbone courses of each disciple of agricultural engineering can realize download of course resources, submission and revision of homework and Q\&A, etc; the study module of each backbone course, relevant skill points and skill trees are uploaded; each module of backbone courses have adequate usual exercise, course training and course exercise, etc. for students to finish online and submit to teachers for checking, and realize whole process monitoring and scientific assessment and evaluation of teaching of backbone courses.

(3) Skill learning progress and data analysis module. This module records students' progress on skill of each course, skill evaluation level, and teachers can analyze and count students' skill data, master and guide students' learning of professional skills.

Construction of Practical Teaching. Establish scientific and technological innovation item relying on all kinds of competition, improve students' innovative ability and comprehensive qualification. cultivate students' awareness and thought of innovation, establish open professional labs. Professional labs are effective carriers for students to participate in innovative experiments, S\&T interest projects, professional skill contest, undergraduate student challenge cup and entrepreneurial plan, realize opening of "experiment time, experiment space, experiment articles and experiment content", students can selectively carry out items according to their own interest and specialties so as to cultivate students' practical abilities.

\section{Results of Practice of Talents Training Program}

Since the training program for innovative talents of agricultural engineering was established and operated, teachers' and students' activity and initiativity of participating in research of teaching reform was motivated and remarkable talents training achievements were obtained. Features of professional training were manifested, and specialty recognition was greatly increased. Agricultural mechanization and automation, agricultural electrification were chosen as pilot specialties for excellent engineer 
training program of Sichuan Province respectively in 2013 and 2014. Undergraduate talent training quality is improved significantly. Students have made outstanding performance in publication of scientific research thesis, edition of textbooks and participation in scientific contests. In the recent three years, students have joined in 18 college students' innovative experiments, 24 scientific interested programs, and 6 professional skill contests. By the end of 2015, it has participated in various kinds of S\&T contests and awarded almost 70 awards at and above provincial level.

\section{Acknowledgements}

The authors gratefully acknowledge the supported by the educational reform project of Sichuan education department (grant number: 2013037).

\section{References}

[1] H.L. Yang. Exploration and practice of agriculture engineering talents training under the idea of "large-scale engineering". Journal of Anhui Agricultural science, pp.12625-12626, 12628, 39(20), 2011.

[2] Sun Bugong, Zhao Wuyun, Wu Jianmin, et al. Systems and foster person with innovation ability in agriculture engineering. Chinese Agriculture Mechanization, pp.91-92, 97, (1), 2009.

[3] Tao Dinglai. Strengthen Research and Practice of Agricultural Engineering, Realization of Agricultural Modernization in China. Agricultural Engineering, 1(3), pp.1-6,2011.

[4] Wang Yanjin, Wang Zhenfeng, Zhang Quanguo, et al. Practice and thinking of agricultural engineering undergraduate education. Journal of Henan Institute of Education (Natural Science Edition), 22(1), pp.68-70, 2013.

[5] Hou Jialin, Li Tianhua, Fu Chenjia, et al. The research and practice of application-oriented undergraduate majoring in agricultural engineering. Higher Agricultural Education, (4), pp.41-44, 2012.

[6] Li Wenzhe, Liu Jianyu. Exploration and Practice on Cultivating Versatile Personnel in Agricultural Engineering $\mathrm{M}$ ajor. Journal of northeast agricultural university (social science edition), 8(1), pp.10-12, 2010.

[7] Wang Hongying, Xu Li-ming, Wang Jicheng. A study on course system reform of practical teaching in agricultural engineering discipline. Chinese Agricultural Mechanization, (6), pp.99-101, 2008.

[8] Yao Xinsheng, Jiao Youzhou, Zhang Quoguo, et al. Study and practice on mode innovation in experiment teaching of agricultural engineering. Journal of Henan Institute of Education (Natural Science Edition), 20(1), pp.60-64, 2011.

[9] Yang Xiaoping, Zhao Chunhua, Zhao Wuyun. Foundation with agricultural engineering training and construction of opening innovation practice platform. Chinese Agricultural Mechanization, (3), pp.170-173,176, 2012.

[10]Jiao Youzhou, Yao Xinsheng, Xu Guang, et al. Research and practice on the experiment teaching reform of the training center of agricultural engineering. Laboratory Science, 13(5), 19-22, 25, 2010 .

[11] Yanag Mingin, Li Yunwu, Yang Ling, et al. Personnel cultivation mode of agricultural engineering discipline of Chongqing. Journal of Southwest China Normal University (Natural Science Edition), 35(6), pp.231-235, 2010. 